\title{
Trauma and reporters: And the reporting of suicide in media
}

Trauma is an inevitable part of everyday life in the Pacific. The media is a powerful force and when used effectively it can help to mobilise assistance for victims and survivors. Sometimes, getting that message across has a psychological cost.

\section{By ANNA SHADBOLT}

THE REALITY of trauma, is that when an event appears to be over, there are often many people still suffering silently from their traumatic experiences. Not only the people who tragically lose their loved ones, but also the many personnel who are involved in the recovery phases that follow as part of their job or profession. These people include the police, emergency workers, airline staff, health workers, journalists and volunteers. Their reaction is called a stress reaction, but in particular, a traumatic stress response.

Disasters and traumatic events, by their very nature are shocking and sudden. The disaster may be a flood, an earthquake, a hurricane, a tsunami, a major accident, a war or civil unrest, but trauma may also result from a suicide, an industrial accident, or a motor car accident where only one death occurs.

This article firstly looks at some information about the psychological impact of trauma followed by a description of various types of traumatic events like disasters and suicide that have occurred in the region. A case study approach will address three key areas for the journalist:

The impact of the reporting on the journalist;

$\square$ The impact of the reporting on the victims, the survivors, and the general public;

$\square$ Reporting of suicide in the media. 


\section{The impact of reporting traumatic events on journalists}

Despite the large amount of research on the psychological impact of trauma on victims and emergency personnel over the past thirty years, little reference is made to the impact on media personnel following such events, yet the media are always there getting information out to the public. More recently, interest on the impact of traumatic stress on journalists is gaining recognition as it becomes acknowledged as a serious occupational health hazard. Some reports from recent disasters in the region illustrate the psychological cost of working in this area.

Tsunami in Aitape, Papua New Guinea

In July 1998 a tsunami virtually engulfed the villages in the Sissino lagoon area. The final death toll is still unknown, but it is estimated at over 2000 people. Sean Dorney reflects on his experience as a journalist working for the Australian Broadcasting Corporation in PNG:

In the 20 odd years I was in Papua New Guinea, I covered many natural disasters and tragedies. But none of them affected me so deeply as did this freak wave, which crashed without warning ... The human tragedy of the Aitape disaster had, I said to them with tears welling in my eyes, no equal in my experience [speaking more than 12 months after the tsunami]. There were undoubtedly tensions between those engaged in the rescue effort ands those trying to report on it ... the helicopter pilot who ... worked tirelessly ... to save many lives ... looked up and saw a cameraman out filming ... he told me he yelled out to those around him, "all he's interested in is the bloody pictures. Why doesn't the bastard get down here and help someone?" (Dorney, 1999)

The massacre at Port Arthur, Tasmania, Australia

In April 1996 an armed gunman killed 35 people, injured 18 and attempted to kill a further 20 people in Port Arthur, a popular tourist destination just south of Hobart in Tasmania. This has been identified as one of the worst massacres by a single gunman, outside a war situation, in the world. Richard Lower reflects on his part in reporting this disaster as the television editor for Australian Broadcasting Corporation in Tasmania:

The last thing to think about was the impact that this was having on the people who were going down to Port Arthur, because I never had to go 


\section{ANNA SHADBOLT}

down there. In fact, I have not been back Port Arthur to this day lover three years] ... I was observing it from a distance ... I started to notice things. I walked past an editing suite and saw an editor crying at the controls... he said, 'I am sick of dealing with this material ... I don't want to cut it any more' ... while bulletins were being aired, the staff operating the autocue at the back of the room burst into tears ... or cadet ... said: "I am having second thoughts about my career options ... I don't think I want to be a journalist any more" ...

... We had to keep putting the material out ... Clearly people were being affected and could not do their job properly ... in this whole process, very few people care about the editor, and I do not recall anyone asking me how I was feeling. All the time I was asking the staff how they were feeling. (Lower, 1999).

The Air Fiji plane crash in Fiji

In July 1999, Fiji experienced its worst plane disaster when flight PC 121, flying from Suva to Nadi, crashed in the Namosi highlands. All crew and passengers

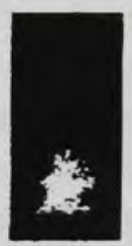

\section{BUSHFIREMEDIA}

Investigative journalism and documentary research, media critique, progressive publishing in print and on the Web, and feature articles for publication. SPECIALIST IN RSIR-PACIFIC REGION

\section{PO Box 9 Annandale, NSW 2038, Australia bfmedia@mpx.com.au}

See Bushfire Media's MEDIA.NET web site at www.mpx.com.au/ bfmedia/ 
died - a total of 17 people. The following information is based on information collected from journalists who were at the crash site.

An early morning call came for a small group of young journalists to head up to Namosi on the July morning of the Air Fiji plane crash. At the time when they left Suva, little information was known about the crash and whether there were any survivors. The thoughts that they had as they started their journey were only of the great story they were going to get - maybe the story of a lifetime, a Pulitzer prize winner! The expectations of the group were enormous.

When they finally arrived at the village they were told that they would need to go a few more hours on foot to get to the crash site. They decided to navigate their way through the inhospitable jungle. There were times alonng the way when they were ready to lurn back as exhaustion set in from carrying heavy photographic equipment - but their youth, enthusiasm and adrenalin kept them going. (Shadbolt, taken from interviews in 1999 and 2000)

Each of these events can be clearly identified as large-scale disasters. The reality though, is that

a traumatic stress response occurs not only in a situation of a major disaster, but also in situations which are characterised as critical incidents. These incidents include any situation faced by an individual that causes him/her to experience unusually strong emotional reactions that have the potential to interfere with their ability to function either at the scene or later. (Mitchell, 199.3) Some other types of critical incidents include:

- Sudden death of a child under tragic circumstances

Any incident which poses a serious physical or psychological threat to the worker him or herself

Multiple fatalities

Exposure to body parts or dismembered bodies, as in an industrial accident

Serious injury or death of a colleague in the line of duty, as has occurred in reporting of conflict situations

A serious injury or death of a member of the public resulting from carrying out of your own duty, e.g. media vehicle collides with emergency vehicle or on-lookers when responding to a call out. 


\section{ANNA SHADBOLT}

Research with emergency workers suggests that everyone is affected to some extent by such events. Such psychological effects of trauma are completely normal, and it is expected that anyone experiencing such shocking and unexpected events would react in a similar way. It is when these stress reactions persist over an extended period of time that more serious mental health problems may develop.

Typical initial reactions following such an event will affect the individual's thinking, emotions and physical functioning. Some effects that have been reported by journalists, police, soldiers, and emergency personnel include those on the opposite page:

There are personal factors that contribute to the response that any individual journalist will experience. These include:

The level of involvement that the individual has at the disaster scene. The

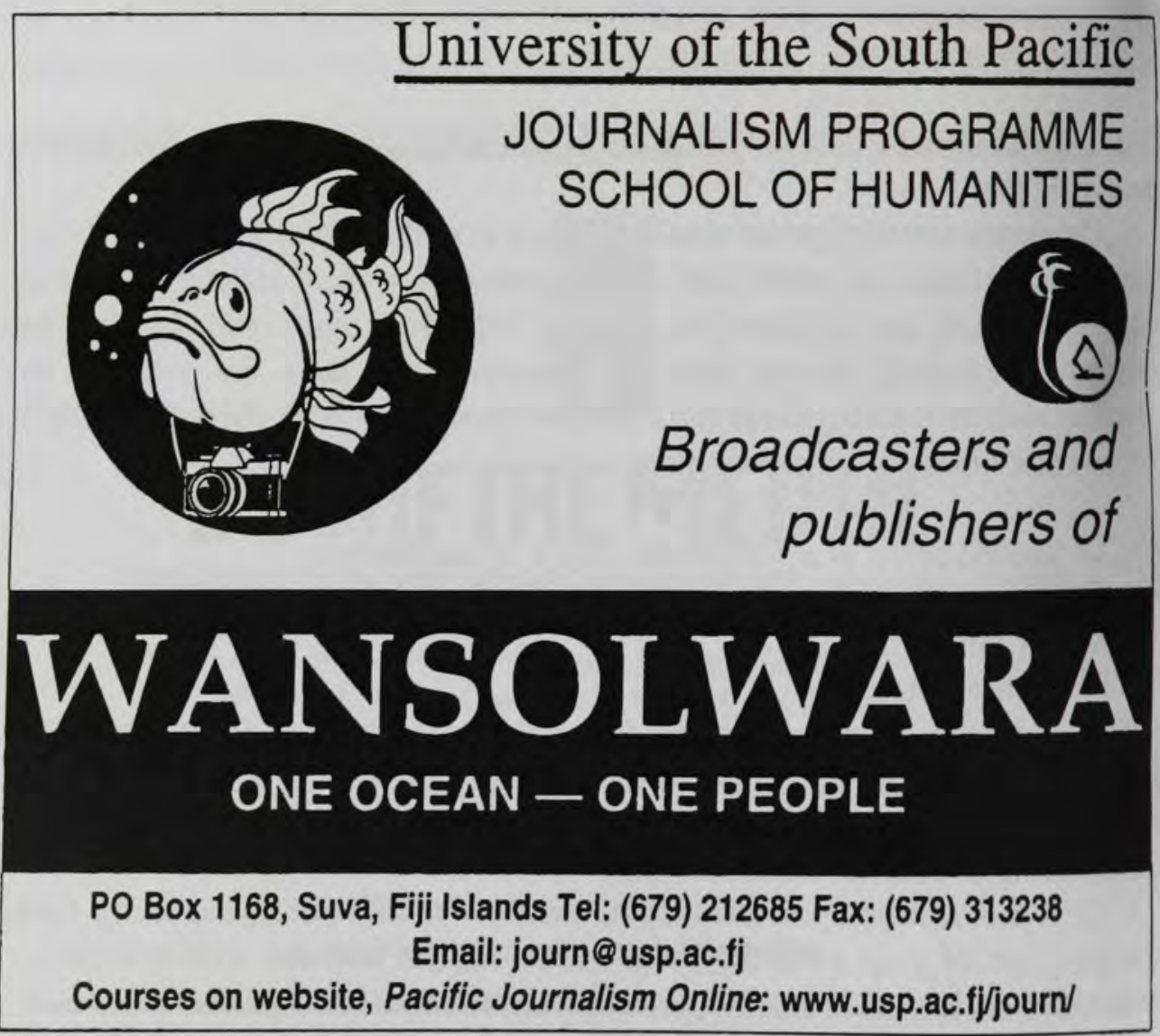




\section{REPORTED EFFECTS}

\section{PHYSICAL}

Nausea

Upset stomach

Tremors/shakes (lips, hands)

Feeling uncoordinated/

clumsy

Heary sweating

Chills

Diarmoea

Dizziness

Chest pain (must check with doctor)

Rapid heart beat

Rapid breathing Increased blood pressure

Headaches

Muscle aches

Sleep disturbance

Loss of appetite

Weight loss

Hyper-alertness

\section{THINKING}

Slowed thinking

Difficulty making decisions

Difficulty in problem solv. ing

Poor attention span

Disorientation (place and Sadness time)

Difficulty with calculations Feeling lost Difficulty concentrating Memory problems

Difficulty naming common objects

Seeing the event over and over

Confusion

Distressing dreams

\section{EMOTIONAL}

Anxiety/worry

Fear

Guilt

\section{Depression}

Feeling abandoned

Feeling isolated

Wanting to limit contact

with others

Wanting to hide

Worry about others

Anger

Irritability

Feeling numb

Easily startled

Shocked

Easily upset

Trauma effects: As reported by journalists, police and emergency services. (Adapted from Mitchell, 1990).

actual first-hand experience with death itself, usually on a large scale, and the extent to which the individual needs to work with the victims, dead bodies and/ or bereaved survivors at the scene, all contribute directly to the psychological impact. For instance, Sean Dorney (1999) refers to the way he was personally involved in recovery of injured survivors at the tsunami in PNG. Journalists who are sent on "death knocks" (speaking to bereaved family of the victim) may be 


\section{ANNA SHADBOLT}

the first ones to inform family of the tragedy.

The way in which each individual assesses the situation. For instance, the individual journalist may become fearful for the safety of his/her own loved ones, or may actually experience direct personal loss from the disaster through losing a loved one. This means that she or he may be attempting to deal with her or his own grief and loss while also trying to report on the large-scale impact of the event on others. This situation would not unexpected given the small size of many Pacific communities, hence adding to the psychological impact of such events on Pacific journalists.

$\square$ Repeated exposure to traumatic events of this nature creates a cumulative reaction whereby one event triggers a powerful response that is a culmination of numerous traumatic experiences.

Negative public image. An added factor that impacts on journalists is the negative public response that often goes hand-in-hand with the job. By their very nature, journalists are viewed as insensitive and self-serving, as was evidenced in the report from Sean Dorney in PNG. In Fiji, the news media were cited before the Media Council because of "insensitive reporting" of the Air Fiji crash. There is no doubt that such a bad public image adds to the stress of an already difficult situation because they are viewed as "unfeeling". There is rarely any empathy given to the distraught journalist who is traumatised from completing his or her job (Castle, 1999).

\section{Coping strategies}

The immediate responses to the feelings of discomfort experienced in the aftermath of the disaster are known as coping strategies. Sometimes these work and sometimes they may add to the problems. Disasters often provoke a fange of problems in social functioning which tend to relate to the emotional response to the experience of the disaster: "irritability leading to interpersonal friction; concentration difficulties leading to problems at work (Williams et al, 1993: 452).

Some typical coping strategies that often do not help are:

Refusing to talk about personal experiences to others Shutting out others

Avoiding activities or situations which bring back thoughts of the traumatic event - affecting all senses: smell, taste, vision, and sounds

$\square$ Burying oneself in extra work 
$\square$ Increased consumption/use of alcohol, tobacco, coffee, and other drugs (Malt et al, 1989, Mitchell \& Bray, 1990, Williams et al, 1993).

All of these strategies were reported in follow-up sessions with journalists and police after the Air Fiji crash. These included avoiding watching TV, taking up special projects which were very time consuming, increased use of alcohol, refusing to write any more stories about the event, not talking about the event 10 anyone (even 10 months later), changing jobs.

Research with emergency personnel has identified more effective coping strategies. Information about these options are usually provided at debriefing sessions as part of the educational component of the process to help individuals exposed to a traumatic event to use more constructive methods for coping with the emotional distress. These short term strategies facilitate the recovery phase and help to prevent more serious mental health problems.

\section{The worst case scenario}

In some cases the person who experiences a traumatic event can develop a serious mental disorder. As mentioned earlier, the way(s) in which an event, and one's involvement in it, is personally assessed, influences the psychological response to a traumatic event. The past experience of the individual is also important here and depending on how all these factors pan out it is expected that 5-20 percent of individuals will suffer from a more serious reaction that may result in Post Traumatic Stress Disorder (PTSD) which is a chronic psychiatric disorder.

Clinical studies with emergency workers and military personnel have shown that a number of factors place people at risk for chronic PTSD. Some of these include:

Nature and intensity of the ștressor

$\square$ Characteristics of the individual victim or helper

$\square$ History of past stressful life experience

$\checkmark$ Characteristics of the recovery environment

The recovery environment includes the workplace itself and the recognition given by management of the traumatic experiences of their workers. Hence, the extent to which journalists are expected to continue working on a story and the need to return to the disaster scene may add to the stress. Dorney (1999: 139). 


\section{ANNA SHADBOLT}

reflects on how his media organisation added to his trauma following the tsunami:

I recognise that I was traumatised by it all, not only because it was a tragic story but also because of the almost impossible demands that were daily, hourly, being put upon me...

Journalists, working at the Air Fiji crash site, were expected to continue with their scheduled rosters on the days following their arduous journey through the jungle, and some were involved in follow-up stories on the recovery of the bodies of victims.

A number of symptoms need to be present for this disorder to occur, which include:

$\square$ Reexperiencing and intrusive phenomena (memories; distress caused by triggers that remind person of event; nightmares that disturb sleep; flashbacks with panic \& sweating responses)

$\square$ Psychological symptoms which are shutting out of feelings, numbing, denying responses

Arousal symptoms: irritability, sleep disturbance, hyper-alertness

However, these symptoms need to persist for three-six months for a diagnosis of PTSD.

Interviews with journalists following the Air Fiji crash indicated that all those interviewed had some of the symptoms that have the potential to lead to PTSD. Castle (1999) reports that journalists he interviewed following the tsunami in PNG showed similar symptoms. However, there has been no systematic surveillance of these stress disorders among journalists or the general community within the Pacific so far.

What is it that stops journalists from seeking help even when the distress they feel is affecting their ability to cope? Place (1992) recounts the aftermath of the Hoddle Street and Queen Street massacres in Melbourne in the late 1980s in his dissertation about the need for counselling services for journalists. He stated that one of the problems in the industry is the sense of "machismo" which infers that you need to be tough - and if you cannot hack it then maybe you are in the wrong industry. Interestingly this is a common theme found among the emergency services like fire-fighters, police and ambulance officers. All are 
male-dominated high-powered work places that have this "culture", and yet in many countries they have moved to recognising the need for psychological support services.

Lower (1999) participated in a debriefing session following the Port Arthur massacre. He said:

Looking back, holding the session was absolutely the right thing to do. People came up to me the next day or two afterwards and said, "Thank God we did that because virtually we were all going home of an evening and not knowing what to do.

There is some disagreement among psychologists about the most effective methods for managing trauma. Despite this, Red Cross International, police and emergency personnel in many countries believe that the debriefing process is an important component. Some journalists who are working in the area of trauma management also argue that the process is useful, especially when incorporated as part of a peer support structure (Place, 1992; Castle, 1999). The effectiveness of peers for psychological support is increasingly recognised as a model that reduces the stigmatisation often associated with such support. For more information about establishing a peer support programme refer to Robinson and Murdoch (1991).

\section{Prevention is better than the cure}

There is increasing recognition that some of these problems are preventable. As media organisations recognise the real impact that working with traumatic events can have on their personnel they start to examine their own systems of support and management. The financial costs of lost man-hours, high staff turnover, and poor productivity will provide the impetus for looking seriously at this occupational health and safety issue within the media industry as it did in the emergency services.

A well-planned preventative approach needs to have three components:

Appropriate management of media coverage of potentially traumatic events The industry needs to look at how the expectations they place on their journalists may add further to the stress that is experienced. As mentioned earlier, Dorney felt that the demands placed on him were excessive. Others have reported that the use of inexperienced journalists on "death knocks" is a poor practice (Place, 1992; Castle, 1999). Place (1992) also states that different media have different 


\section{ANNA SHADBOLT}

needs and protocols, i.e. print, radio, television and internet. Each sector needs to review its practices in light of this knowledge and experience.

Pre-trauma education of personnel about the psychological impact of trauma

Basic training in journalism, whether at a university or on the job, needs to incorporate some training about trauma, its impact on the individual and its management. The information contained in this chapter and the resources listed at the end provide a good starting point for developing a knowledge base in this field. An elementary understanding of human behaviour, emotions like grief, problem solving and stress are key areas of psychology that would add to this information.

Adequate follow-up care and support for those who work with traumatic material, both at the scene and back in the newsroom. Typical guidelines used by emergency personnel in countries like Australia and the United States for those who are exposed to serious critical incidents or traumatic events are compulsory debriefing following critical incidents, peer support networks, and provision of professional counselling services. This is not the case with emergency personnel in Fiji. In fact, when debriefing and counselling services were offered, by the Red Cross and the National Advisory Council on Mental Health, following the Air Fiji crash, only a few police and journalists used them.

As stated earlier, there are often barriers to seeking help. Place (1992) suggests that with the right leadership and training, the media industry in Australia could establish and in-house peer support network for managing trauma. This model is consistent with the informal networks that develop within the Pacific. The access to internet facilities could help the isolated journalist access a trained peer for psychological support. The impetus for such a programme needs to come from the industry itself.

\section{The impact of reporting on the victims, survivors and public}

Journalists are not the only victims of media coverage of trauma - the consumers of the reporting are also potential victims of trauma. Research has shown that victims, survivors, families, friends, and communities, use media coverage to help them find meaning in the disaster or traumatic event that has occurred (McLellan, 1999). While reporters may regard their work as today's news, the affected public, repeatedly examine media reports to help them make sense of the, often senseless, event.

McLellan $(1999,59)$ found that various media reports and images following 150 PACIFIC JOURNALISM REVIEW 7:1 2001 
TRAUMA AND REPORTERS the Port Arthur massacre and various industrial accident deaths in Australia triggered distressing responses. Some of these responses included:

Physical stress symptoms: increased heart rate, palpitations, cold sweats Horrendous flashbacks

Disturbing dreams

Deep depression

Substance abuse

Episodes of self-mutilation

Suicide ideation or attempts

These responses occurred after the event or even months later, especially at anniversaries or times when some similar event resulted in recycled details, often with no warning.

Some of the reports that followed the Air Fiji crash in 1999 were considered insensitive and inconsiderate of the families of the victims as well as disturbing to the general public. Some articles used very graphic language that enabled the reader to readily visualise the horror of the scene - an exercise that may result in a traumatic reaction, especially for the family and loved ones of these victims so described (Shadbolt, 200:290-291). Morbid headings are somewhat disturbing as they may start family members of victims imagining that their loved ones had been mutilated. This style of reporting was not restricted to the print media, but also on radio and television. The community backlash against this style of reporting of this tragedy resulted in submissions to the Fiji Media Council.

In its ruling, the Media Council recognised that journalists in Fiji had had little exposure to such disasters and hence lacked experience in dealing with such material. It also acknowledged the important role that media must play in reporting such tragedies to the public. Overall it asserted that the Council's Code of Ethics, which was not in use at the time of the plane crash, now provides adequate guidelines for future reporting of such disasters, particularly two sections:

U DISTRESSING MATERIAL: Editurs, producers and broadcasters of news, current affairs and documentary programmes should take particular care in deciding whether the inclusion of graphic detail and intensity of violent or distressing material is warranted by its relevance and to aid public understanding of the subject. Special consideration must be given 


\section{ANNA SHADBOLT}

to possible transmission of particularly disturbing images... (Section 6, Broadcasting [Television and Radio] programme Code of Practuce)

$\square$ TASTE AND DECENCY: They should not include material which is offensive to prevailing general standards of taste and decency, or likely to prejudice respect for human dignity among its audience bearing in mind the manner and time of transmission (Section 1, ibid.).

Such guidelines provide an excellent framework for guiding responsible reporting. But they cannot stand alone for they lack sufficient rationale for their existence in the case of dealing with traumatic events. It is imperative that editors, producers and broadcasters understand the nature of trauma and its impact on people, including themselves and their reporters, before they are able to make such judgements. For instance, when the report of the Air Fiji crash appeared on the current affairs program on Fiji One it was obvious to the trained viewer that the reporter was himself traumatised, and hence unfit to judge how to regulate the amount of information to give. It had been less than 24 hours since he himself had been subjected to the horrific crash site.

McLellan (199: 64-66) presents a scathing report of the poor practice of Australian media personnel following the Port Arthur massacre in 1996. She reports about the insensitivity that prevailed in getting the story at any cost. Her findings identify three main areas of concern:

- Legal/ethical/moral issues that concern and/or distress those dealing with the media after a traumatic event;

$\square$ Dubious practice in the field

Newsroom and publication decisions that cause further alarm

McLellan (1999: 66) provides some pertinent reasoning for the malpractice that was evident from her study. Some of her perceptions that are pertinent to this region include:

Young inexperienced journalists believe that their career will be on the line if they do not deliver

$\square$ Decision-makers under-estimate the number of people potentially traumatised by an event

$\square$ Despite industry-wide code of ethics... distribution and discussion of best practice information related to the covering of traumatic events is patchy

$\square$ Journalists and decision-makers receive little training about trauma and 152 PACIFIC JOURNALISM REVIEW 7:1 2001 


\section{TRAUMA AND REPORTERS}

its impacts

Journalists and decision-makers are not encouraged to reflect on the ramifications of their actions

Journalists and decision-makers use deadlines and competition to excuse malpractice

More sensitive approaches to victims and survivors will help both parties and increase the job satisfaction of the journalist. For instance, when sent out on a "death knock", making the effort to place greater focus on the needs of the interviewee rather than on the story. Cote and Bucqueroux (1996, cited McLellan, 1999) provide some tips for the interviewing in such situations which are provided here as a guide for better practice.

The reporting of traumatic events is difficult and challenging. As professionals, journalists must decide what is important to report and what is not. Ethical guidelines already exist to help this judgement to be made. As one becomes more knowledgeable of the costs associated with reporting trauma, one is in a better position to judge the stories that are best left only half told.

The next section looks at another difficult area of reporting. Suicide is treated separately as there are some special aspects that relate only to this area of reporting.

\section{Reporting of suicide in the media}

As mentioned in the previous section, people use media reports to help them understand and give meaning to events that occur in their communities. Research in many countries throughout the world have shown that when media sensationalises or gives prominence to the reporting of suicide there can be an increase in the rate of suicide - referred to as copycat suicides. This creates a difficult dilemma over the reporting of suicide. In countries like Australia, very few suicides are ever reported in the media (Herman, 1996). This is not the current practice of the print media in Fiji.

In 1999, on Christmas Eve and again on New Year's Eve, eager school children awaited the early results of their examination performance. These would be published in the print media for all of Fiji to see. The front page of The Fiji Times on 5 January 2000 saw the headline:

EXAM FAILURE TRIGGERS SUICIDE 
This was an article that reported the suicide of a young 16-year girl from poisoning, allegedly because she had failed her Fiji Junior (Form 4) examinations. Following the publication of this article considerable follow-up coverage was published and broadcast in the media.

Suicide is a serious mental health problem in many Pacific Island countries. Police statistics for Fiji show that for the months of January and February 2000, there were 23 deaths by suicide and 21 non-fatal suicide attempts reported to police. Police state that accurate data collection is often difficult, especially for non-fatal attempts, where medical attention is not required, as families tend not to report the matter to police. The statistics for Fiji do not attempt to prove that there were copycat suicides following the article on January 5, but they do show that there are many vulnerable people in the community. The media industry needs to be aware of the potential impact that reporting may have on the behaviour of its readers.

In Australia, the federal Ministry of Health and Aged Care, has developed a media package for the reporting of suicide as part of its suicide prevention strategy. A summary of their suggestions is provided in the table on the opposite page. Each suggestion provides a rationale for its inclusion in these guidelines.

If we refer back to the Fiji Times article referred to earlier we can assess the extent to which it conformed to these guidelines.

Key concerns about the reporting of this juvenile suicide are:

The article was on the front page [Refer to point 1]

$\square$ The headline was sensational - linking exam results to the untimely death of the child and used the word "suicide" [Refer 3,7$]$

- The article provided precise details of the suicide method used [Refer 4]

- The journalist interviewed the parents of the young victim. [Refer 8,9]

- The article included statements that infer some level of neglect or responsibility on the part of parents/family for the tragedy [Refer 8,9$]$

$\square$ The article did not provide any contacts or mental health messages suggesting that help is available for readers who may be in a vulnerable mental state. [Refer 10]

The Fiji Times article contravened many of the suggested guidelines for the reporting of suicide. Admittedly it is unlikely that the reporter had access to this material but when I approached the editor of the paper and offered information about the problems in their reporting of suicide little interest or concern was expressed and the offer was declined. This attitude demonstrated a certain level of naiveté about common practice in the reporting of suicide in the press.

154 PACIFIC JOURNALISM REVIEW 7:1 2001 


\section{QUICK MEDIA GUIDE ON SUICIDE}

1. Place the relevant story on the inside pages of a newspaper, magazine, journal in the second or third break of TV news, or further down the order of radio reports rather than making it a headline, front page or top of the bulletin piece.

Researchers have discovered a link between front page of prominent stories and increased incidence of copycat suicide. Prominently featured stories are more noticeable and given greater weight in terms of importance of notoriety to audiences. This can make suicide a more credible course of action to some vulnerable people.

2. Don't constantly repeat stories on suicide, especially on TV and radio have the effect of normalising suicide for viewers and listeners.

People can become "desensitised", as they do to many forms of violence or harm, through constant exposure and repeated messages.

3. Use the word "suicide" sparingly and cautiously.

Evidence suggests reports that are highly emotionally charged, which use sensational headlines, and/or which have an over-emphasis on the word "suicide" are more likely to encourage imitation suicide.

4. Don't use overly explicit descriptions, photographs or footage of the method and location - they can be particularly dangerous.

A step by step description can provide an impetus and mechanism for some vulnerable people.

5. Be careful with celebrity suicides - consider the repercussions.

Recent research has found that reporting of celebrity suicides can influence suicide rates in some cultural contexts and times. The air of tragedy and the almost "legendary" status of celebrity suicides can, unfortunately, add to the perceived glamour and attraction of suicide for some young people.

6. Try to give the bigger picture to help educate people about suicide.

Stories on the strong relationship between mental illness and suicide risk - for example, depression as a risk factor for suicide - can help to place the situation into context. It can also help people understand it is not a separate one-step event but that it is part of a bigger problem and challenge for society. 


\section{QUICK MEDIA GUIDE ON SUICIDE continued}

\section{Avoid glamorising suicide in dramatic presentations.}

In depicting suicide as part of a storyline in a drama, emphasise the devastation following the act rather than focusing too heavily on the act itself. Also stress the finality and don't overdramatise the act.

8. Remember: The bereaved are often at risk themselves.

Professional ethical guidelines and industry codes of practice for contact with the bereaved is the best guide

9. Some suggestions for language:

$\square$ Instead of referring to a first suicide attempt as "unsuccessful", try saying the first suicide attempt was "not fatal".

$\square$ Rather than reporting a "suicide epidemic", talk about increasing rates. It may not be a powerful but it is more accurate.

Instead of referring to a person as a "suicide" or a "depressive", use terms such as "died by suicide" or "the person was depressed at the time of his or her death".

If it is necessary to describe the method of suicide, then instead of saying "the woman died after placing a hose inside her car window" simply state that "the woman died of asphyxiation".

Replace descriptions like a "bizarre suicide pact", by saying "the deaths were allegedly planned by the couple".

\section{Promote the use of mental health services.}

Including phone numbers and details of local help services or mental health services at the end of a report offers people immediate assistance. This is particularly important if the story has distressed them or prompted thoughts of suicide. Where appropriate, include the National Help Line numbers like St Giles Hospital in Fiji, or a medical practitioner, psychologist or social worker.

(Taken from Department of Health and Aged Care, Australian Government, 1999) 
TRAUMA AND REPORTERS

The National Advisory Council on Mental Health in Fiji, is in the process of developing policy guidelines for reporting of suicides in Fiji in consultation with the Fiji Media Council and various media organisations and interested bodies within Fiji.

\section{The need for best practice}

Trauma is an inevitable part of everyday life in the Pacific. The media is a powerful force and when used effectively it can help to mobilise assistance for victims and survivors. Sometimes, getting that message across has a psychological cost. The recognition and management of that cost will ensure that journalists and the general public benefit from the process.

As part of a fledgling media industry, it is important that Pacific journalists work towards achieving best practice while also ensuring the maintenance of their own and their community's psychological well being.

\section{Bibliography:}

Australian Commonwealth Department of Health and Aged Care (1999) "Achieving the balance: A resource kit for Australian media professionals for the reporting and portrayal of suicide and mental illness." Publications Production Unit: Canberra, Australia.

Cote, W. and Bucqueroux, B. (Fall 1996) "Tips on interviewing victims." In Neiman Reports.

Dorney, S. (1999) "Covering catastrophe in Papua New Guinea." Asia-Pacific Media Educator, Issue No. 7: July-December 1999: 137-142.

Castle, P. (1999) "Journalism and trauma: proposals for change." Asia-Pacific Media Educator, Issue No. 7: July-December 1999: 143-150.

Herman, J. R. (Ed), (1996) The Reporting of Suicide: Particularly Youth Suicide. Twentieth Anniversary Papers, Volume 1, Sydney: Australian Press Council.

Lower, R. (1999) "Port Arthur Massacre: A TV editor's experience." Asia-Pacific Media Educator, Issue No. 7: July-December 1999: 124-130.

Malt, UF, Blika, G., \& Hoivik, B. (1989) "The late effects of accidental injury yuestionnaire." Acta Psychiatrica Scandinuvica Supplementum, 353, 59-64, cited in Raphael, B. \& Meldrum, L. (1994) "Helping people cope with trauma." IN Watts, R. and de L Horne, D.J. (eds) (1994) Coping With Trauma: The Victim and the Helper. Brisbane: Australian Academic Press, pp 1-20.

McLellan, T. (1999) 'Fair game or fair go? Impact of news reporting on victims and survivors of traumatic events." Asia-Pacific Media Educator, Issue No. 7: JulyDecember 1999: 53-72. 


\section{ANNA SHADBOLT}

Mitchell, J. T., \& Bray, G., (1990) Emergency Services Stress, Engelwood Cliffs, New Jersey: Prentice-Hall

Place, N. (1992) "Journalists and trauma: the need for counselling." Australian Studies in Journalism. Volume 1, 1992

Robinson, R., and Murdoch, P., (1991) Guidelines for Establishing Peer Support Programs in Emergency Services. Booklet printed by The Victorian Combined Emergency Services Critical Incident Stress Advisory Committee, Waterwheel Press, Melbourne, Australia

Raphael, B., (1983) The Anatomy of Bereavement. New York: Basic Books.

Raphael, B. and Meldrum, L. (1994) "Helping people cope with trauma." In Watts, R. \& de L Horne, D.J. (eds) (1994) Coping With Trauma: The Victim and the Helper: Brisbane: Australian Academic Press, pp 1-20.

Revel, JP (1999) "Psychological support in disaster." Unpublished paper, Psychological Support, International Red Cross.

Shadbolt, A. (2001) "Trauma and the reporter". In Robie, D. (2001), The Pacific Journalist: A Practical Guide. Suva: University of the South Pacific Journalism Programme.

Watts, R. and de L Horne, D.J. (Eds) (1994) Coping With Trauma: The Victim und the Helper. Brisbane: Australian Academic Press

Williams, R., Joseph, S., \& Yule, W. (1993) "Disaster and mental health." In Principles of Social Psychiatry by Bhugra, D. \& Leff, J. (Eds) Oxford: Blackwells Scientific Publications, pp 450-469.

Anna Shadbolt is a psychologist. At the time of writing this article, she was at the University of the South Pacific and a member of the National Advisory Council on Mental Healh in Fiji. She has been researching the impact of media coverage of disasters and traumatic incidents on journalists. A shorter version of this article was published in The Pacific Journalist. 